\title{
Ser homem com doença falciforme: discursos sobre adoecer e cuidar de si
}

Being a man with sickle cell disease: discourses about falling ill and self-care Ser hombre con anemia falciforme: discursos sobre enfermarse y cuidar de sí mismo

\author{
Anderson Reis de Sousa ${ }^{1}$ ib hittps://orcid.org/0000-0001-8534-1960 \\ Adriana Castro de Jesus ${ }^{2}$ io https://orcid.org/0000-0001-7739-0471 \\ Rúbia Cássia Souza de Andrade² $\circledast$ ittps://orcid.org/0000-0002-8960-0293 \\ Thallys Fabricio de Almeida Lopes² ${ }^{2}$ io htps://oricid.org/0000-0003-3398-4504 \\ Coretta Melissa Jenerette ${ }^{3}$ ic https://orcid.org/0000-0002-9851-4768 \\ Evanilda Souza de Santana Carvalho ${ }^{4}$ ic https://orcid.org/0000-0003-4564-0768 \\ Álvaro Pereira ${ }^{1}$ ib https://oreid.org/0000-0003-1615-5528
}

Sousa AR, Jesus AC, Andrade RC, Lopes TF, Jenerette CM, Carvalho ES, et al. Ser homem com doença falciforme: discursos sobre adoecer e cuidar de si. Acta Paul Enferm. 2021;34:eAPE03384.

DOI

http://dx.doi.org/10.37689/actaape/2021A003384

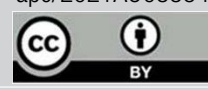

Descritores

Masculinidade; Saúde dos homens; Anemia falciforme; Hemoglobinopatias; Doença crônica

Keywords

Maculinity; Men's health; Anemia sickle cell; Hemoglobinopathies; Chronic disease

\section{Descriptores}

Masculinidad; Salut del hombre; Anemia de células falciformes; Hemoglobinopatias; Enfermedad

crónica

Submetido 23 de Janeiro de 2020

Aceito

20 de Agosto de 2020

Autor correspondente Evanilda Souza de Santana Carvalho E-mail: evasscarvalho@yahoo.com.br

\section{Resumo}

Objetivo: Compreender a experiência da masculinidade no adoecimento de homens com doença falciforme e os desafios para cuidar de si.

Métodos: Estudo descritivo, qualitativo, desenvolvido em um Centro de Referência para acompanhamento das pessoas com doença falciforme. Participaram 13 homens adultos com doença falciforme, que responderam ao desenho-estória com tema e entrevista semiestruturada. Os dados foram submetidos à análise do Discurso do Sujeito Coletivo.

Resultados: Os discursos dos homens com doença falciforme foram organizados em quatro ideias centrais: Descobrir-se enfermo, conhecer a doença e assumir o autocuidado; As limitações impostas pela doença perpassam as masculinidades; Estigma e discriminação acrescem o sofrimento causado pela doença; Homem também sente dor e precisa cuidar de si.

Conclusão: 0 modelo de masculinidade hegemônica é contrariado pelas limitações do adoecimento a pelo aprendizado do autocuidado, promovendo a ressignificação do ser homem a partir da experiência da doença crônica.

\section{Abstract}

Objective: To understand the experience of masculinity in the illness of men with sickle cell disease and the challenges for self-care.

Methods: This descriptive and qualitative study was developed in a reference center for monitoring people with sickle cell disease. Thirteen adult men with sickle cell disease participated, who responded to a drawingstory with a theme and a semi-structured interview. Data were analyzed by Collective Subject Discourse.

Results: The discourses of men with sickle cell disease were organized into four central ideas: Finding oneself ill, knowing the disease and performing self-care; The limitations imposed by the disease permeate masculinities; Stigma and discrimination add to suffering caused by the disease; Men also feel pain and need to take care of themselves.

Conclusion: The hegemonic masculinity model is contradicted by limitations of illness and by learning of selfcare, promoting the resignification of being a man based on the experience of chronic disease. 


\section{Resumen}

Objetivo: Comprender la experiencia de la masculinidad en hombres enfermos con anemia falciforme y los desafíos para cuidar de sí mismo.

Métodos: Estudio descriptivo, cualitativo, llevado a cabo en un Centro de Referencia para seguimiento de las personas con anemia falciforme. Participaron 13 hombres adultos con anemia falciforme, que respondieron al dibujo-cuento con tema y entrevista semiestructurada. Los datos fueron sometidos al análisis del Discurso del Sujeto Colectivo.

Resultados: Los discursos de los hombres con anemia falciforme fueron organizados en cuatro ideas centrales: Descubrirse enfermo, conocer la enfermedad y asumir el autocuidado; Las limitaciones impuestas por la enfermedad atraviesan las masculinidades; El estigma y la discriminación aumentan el sufrimiento causado por la enfermedad; El hombre también siente dolor y necesita cuidarse a sí mismo.

Conclusión: El modelo de masculinidad hegemónica se ve desafiado por las limitaciones de la enfermedad y por el aprendizaje del autocuidado, lo que promueve la resignificación del ser hombre a partir de la experiencia de la enfermedad crónica.

\section{Introdução}

A doença falciforme é a condição hereditária de maior prevalência no mundo. No Brasil, afeta cerca de $0,3 \%$ a $0,5 \%$ da população negra. ${ }^{(1)}$ Caracterizase por anemia hemolítica crônica, vaso-oclusáo e lesão vascular progressiva que afeta múltiplos sistemas orgânicos, trazendo consequências agudas e crônicas, como episódios de dor aguda, síndromes de dor crônica, síndrome torácica aguda, anemia, acidente vascular cerebral e infarto cerebral silencioso, disfunção cognitiva e hipertensão pulmonar, dentre outras, causando intenso sofrimento físico e psíquico aos adoecidos. ${ }^{(2-4)}$

No Brasil, homens com doença falciforme vivem em média 53,3 anos, enquanto as mulheres vivem 56,5 anos. ${ }^{(3)}$ Homens, em geral, possuem menos adesáo ao tratamento de doenças crônicas, visto que os esquemas terapêuticos exigem grande empenho dos adoecidos para incorporação de hábitos de vida e manutençâo de uma disciplina rígida de cuidados.

O rastreamento da doença falciforme foi incluído no Programa Nacional de Triagem Neonatal em 2001, contribuindo para a instituição de cuidados desde as primeiras semanas de vida. $\mathrm{O}$ objetivo desse rastreamento era prevenir e retardar complicaçôes, bem como tratá-las precocemente. Pessoas nascidas antes dessa data podem acessar o diagnóstico de forma tardia e somente a partir da expressão de complicaçóes. ${ }^{(3,4)}$

A assistência à saúde dos homens ganhou novo direcionamento a partir da Política Nacional de Atenção Integral à Saúde do Homem, estabelecida em 2009, pela Portaria 1.944 do Ministério da Saúde. (5) No que tange aos homens com doença falciforme, os serviços que lhes são oferecidos necessitam seguir as diretrizes estabelecidas pela Política Nacional de Atenção Integral às Pessoas com Doença Falciforme, com vistas a desenvolver estratégias de atenção integral, diminuir as complicaçóes e melhorar a qualidade de vida. Tais iniciativas de caráter político têm pautado, em suas diretrizes, perspectivas centradas nas questôes relacionais de sexo e raça, considerando a influência desses marcadores na construção social das masculinidades e no modo como se dão as necessidades de saúde, as vulnerabilidades, o adoecimento e as práticas de cuidado. ${ }^{(6)}$

Considerando que o adoecimento e o cuidado são fenômenos sociais atravessados por discursos, valores e normas atribuídos ao sexo, esta pesquisa buscou responder à questão: Como os homens vivenciam a experiência de ser homem, adoecer e cuidar de si na doença falciforme?

O objetivo deste estudo foi compreender a experiência da masculinidade no adoecimento de homens com doença falciforme e os desafios para cuidar de si.

\section{Métodos}

Estudo descritivo, qualitativo, desenvolvido em um centro de referência para pessoas com doença falciforme no estado da Bahia, na Regiáo Nordeste do Brasil. Esta pesquisa integra um outro projeto, intitulado Produção do Cuidado e Tecnologias Sociais para a Atenção e Educação em Saúde de Homens no Município de Salvador, Bahia, Brasil, e foi aprovada pelo Comitê de Ética em Pesquisa, sob o parecer de 3.313.517. Para alcance do rigor e da qualidade pretendidos, atendeu aos 32 itens de verificação 
dos Consolidated Criteria for Reporting Qualitative Research (COREQ) relativos a equipe de pesquisa, ao projeto de pesquisa e a análise dos dados. ${ }^{(7)}$

Foram convidados 18 homens com 18 anos ou mais com diagnóstico de doença falciforme. Destes, cinco foram excluídos por se queixarem de dor no momento do encontro, resultando no total de 13 participantes entre 18 e 60 anos, autorreferidos negros, com baixa escolaridade e renda familiar média de um salário mínimo.

A aproximação com os participantes ocorreu na sala de espera, no consultório de enfermagem. A coleta de dados se deu entre março e junho 2018, em sala privativa, com a presença apenas do entrevistador do sexo masculino e do entrevistado. A decisão de a entrevista ser realizada por homem se justifica pelo fato de os próprios participantes terem sinalizado, em conversas com o grupo de pesquisa, que se sentiam mais à vontade para falar de suas experiências sobre adoecimento com outro homem, principalmente devido às questôes relacionadas à intimidade, à sexualidade e às vivências do priapismo. Os homens responderam a desenhos-estórias com tema e entrevistas semiestruturada. Os discursos e as estórias obtidos por ambas as técnicas foram gravados e posteriormente transcritos na íntegra pelo primeiro autor. ${ }^{(7)}$

Os dados foram processados no software $\mathrm{NVivo}{ }^{\circ}$, o qual permitiu a extraçáo da nuvem de palavras e dos recortes de falas, que foram analisados a partir do método do Discurso do Sujeito Coletivo, o qual desvelou as expressóes-chaves, as ideias centrais e as ancoragens, para a formulação dos discursos-síntese. ${ }^{(8)}$ As ideias centrais foram validadas pela equipe de pesquisa, composta por três graduandos em treinamento de Iniciação Científica, um doutorando e duas doutoras. ${ }^{(7)} \mathrm{A}$ interpretação dos resultados foi fundamentada no referencial de masculinidades. ${ }^{(9)}$

\section{Resultados}

As experiências das masculinidades no adoecimento de homens com doença falciforme, desveladas nas categorias descritas a seguir, são respaldadas pela nuvem de palavra (Figura 1).

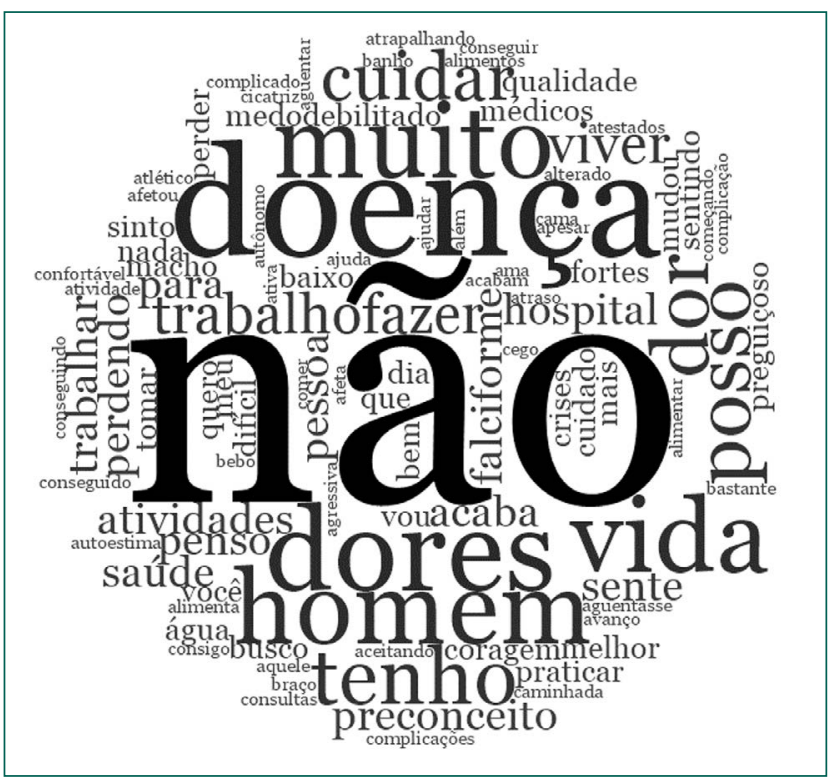

Figura 1. Nuvem de palavras sobre as experiências da masculinidade e do adoecimento de homens com doença falciforme

As palavras expressam a essência das ideias centrais do estudo. Entre as de maior frequência - e, consequentemente, maior expressividade, desvelam-se as vivências de rotinas cotidianas geradas pela doença falciforme na vida dos homens ("dor", "hospital" e "consultas"), que revelam a presença de impactos ("preconceitos") e limitaçōes ("alterado", "mudou", "não posso", "não consigo" e "não sou mais o homem que era antes"), afetando também sua masculinidade.

As quatro ideias centrais apreendidas do material empírico são apresentadas e descritas a seguir.

Ideia central A: Descobrir-se enfermo, conhecer a doença e assumir 0 autocuidado

$\mathrm{O}$ discurso dos homens sobre as vivências ao obter o diagnóstico da doença descreve a trajetória de consultas e exames, os sintomas que evidenciaram o surgimento de complicaçôes, a ênfase dada às dificuldades enquanto consequências da doença, as interaçôes com profissionais de saúde, as medidas terapêuticas e a adoção de novas práticas de cuidado.

"Assim que descobri a doença falciforme, foi aquele susto, achei que iria ficar mais debilitado, que não poderia fazer e nem comer nada. Comecei a tomar todos os cuidados com minha saúde. Passei por médicos, comecei a fazer exames, passei a me 
alimentar nos horários certos, comendo frutas, verduras, retirando refrigerante e alimentos que faziam mal, a exemplo do sal, gordura e o álcool. Depois que descobri essa doença, mudou muito, principalmente por não conseguir aguentar as dores musculares e as crises dolorosas pelo corpo inteiro, fazendo com que eu necessite tomar muitos medicamentos fortes e constantemente ter que ir em busca de um fisioterapeuta. Além disso, perdi um pouco do movimento que eu tinha antes em um dos braços e também sofro com o priapismo. Com o avanço da doença, não posso mais correr, entrar em contato com água fria e fazer esforço físico. Tenho que tomar muito cuidado para não me ferir, devido aos problemas de cicatrizaçáo que eu vivencio. Para evitar esses problemas, eu tento usar um calçado confortável, a fim de poder praticar atividade física, como a caminhada, a musculação e o futebol. Para poder realizar essas atividades eu bebo bastante água a fim de me recuperar e também busco por informaçôes na internet, no Google, como forma de melhorar a minha qualidade de vida." (DSC de homens em vivência da doença falciforme).

\section{Ideia central B: As limitações impostas pela doença perpassam a masculinidade}

Os homens destacam o ideal masculino pautado pela força e pela virilidade, o qual gostariam de alcançar, além das baixas expectativas de colocar em prática seus planos de realização pessoal, como, por exemplo, a construção de uma ocupação profissional e a ascensão no mundo do trabalho. Foram lembradas dificuldades percebidas no exercício da atividade sexual com suas parceiras, que vão desde dores em todo o corpo, que os desanimam de tomar iniciativa para o sexo, até a disfunção sexual, enquanto consequência do priapismo.

"Eu nunca estou com a saúde 100\%, pois é uma doença que necessita de muito cuidado. $\mathrm{Na}$ mesma hora que eu estou bem, estou sentindo dores, e isso me deixa muito debilitado, convivendo diariamente com alguma complicação. Se eu aguentasse, iria trabalhar de carteira assinada, mas infelizmente não posso, porque sinto dores, não posso perder noite e passar da hora de me alimentar. Hoje em dia, não tenho mais aquele vigor e força para realizar deter- minados serviços que são oferecidos no mercado de trabalho, como aqueles que têm atividades pesadas e, como homem, isso me afeta. Ultimamente, eu tenho sido autônomo para me manter, mas o que eu queria mesmo era trabalhar ter a minha vida ativa novamente. Para estudar, eu tenho dificuldade, pois o meu pensamento fica mais lento para leitura e a escrita. Não posso malhar utilizando a força física e, com isso, não posso ter aquele corpo definido e atlético que eu gostaria e isso mexe com a minha autoestima. Fico mais dependente do hospital, mais restrito, e tudo isso tem alterado o meu futuro. Afetou também a minha vida sexual, porque muitas vezes eu acabo não conseguindo praticar, devido às dores. Às vezes é preciso interromper a relação e só voltar depois das dores diminuírem. Acabo perdendo a vontade, não tenho prazer, e por conta disso, não posso me relacionar com uma pessoa normal. Isso acaba com a masculinidade do homem e também afeta a minha disposição para viver." (DSC de homens em vivência da doença falciforme).

\section{Ideia central C: Estigma e discriminação acrescem o sofrimento causado pela doença}

Os homens recordam os rótulos que lhes são atribuídos por aqueles que não conhecem ou não compreendem a doença, as implicaçóes desse desconhecimento para as oportunidades de acessar e se manterem no mercado de trabalho, bem como as dificuldades de atender fisicamente aos trabalhos destinados àqueles que não alcançaram o desempenho escolar e qualificar-se para trabalhos considerados menos "pesados". A discriminação faz com que os homens percebam a incerteza sobre seu futuro, e o risco da exclusão os conduz a trabalhar mesmo padecendo de dor.

"Às vezes quero fazer as atividades e não consigo, e ouço das outras pessoas que eu sou um preguiçoso. Muitas dessas pessoas, não sabem a dor que eu sinto. No momento que eu tive uma isquemia, fiquei depressivo, com medo de ficar cego, pois dormi bem e quando eu acordei fui perdendo a visão em ambos os olhos. Nos momentos das dores fico muito para baixo, muitas vezes penso em desistir, porque as dores são muito fortes. Uma doença dessa é como um atraso de vida, que deixa você para baixo. É uma 
doença agressiva, que gera crises, me levando muito ao hospital, atrapalhando o meu dia a dia. Por conta dessa doença há vários preconceitos, e se a pessoa não tiver ajuda ela entra em depressão. Já tive que ir várias vezes trabalhar sentindo dor, náo podendo falar com o patrão, pelo medo de ser demitido, pois meu patrão não entende o meu problema de saúde, da minha necessidade de ir constantemente ao hospital para tomar medicação, não aceita os atestados médicos e desconta a falta do dia não trabalhado no salário.” (DSC de homens em vivência da doença falciforme).

\section{Ideia central D: Homem também sente dor e precisa cuidar de si}

Os discursos apontam o machismo presente nas percepçóes dos homens sobre o cuidado e revelam que a experiência do adoecimento os leva a elaborar uma narrativa mais positiva em direção ao autocuidado, fundamentando sua busca na esperança pela extensão da vida com qualidade. Assim, os homens descrevem o cotidiano de cuidado para adaptação às adversidades promovidas pela doença e reforçam a necessidade de cuidados de promoção da saúde, para a prevenção ou retardo de complicaçóes.

"Na verdade, o homem foca mais em trabalho. Está mais preocupado com as despesas, outras coisas, e acaba descuidando. Relaxa, pois ele sabe que, se parar um pouquinho, estará perdendo tempo e dinheiro. Há também um preconceito de si mesmo, pois o homem não tem coragem de se abrir, não tem coragem de falar a verdade, porque ele mesmo tem o preconceito, e acha que homem náo sente dor, porque é macho. Quando encontra um homem que se cuida, há uma descriminação da sociedade, que vê essa questão com tabu. Pensam logo que o homem é fresco, mole. Mas eu penso que se eu me cuidar vou viver mais e náo vou perder o melhor da vida, que é chegar na velhice. O homem tem que se cuidar, ele precisa procurar o serviço de saúde por obrigação e não só quando sentir dor, ele necessita ir frequentemente, procurar fazer exame de rotina, principalmente quando chegar à velhice, para ter uma melhor qualidade de vida. Apesar de muitos terem preconceito de que homem é macho e não sente dor, penso que todos têm que se cuidar, pois o cuidar não é só para quem sente dor e sim para quem se ama e quer uma vida longa, e como eu tenho a doença falciforme, se eu não me cuidar, ficarei ainda pior. Eu quero ver meus filhos, netos crescerem, ter uma vida saudável sem complicações, evitando que eu venha estar em uma cama ou dependendo de outra pessoa." (DSC de homens em vivência da doença falciforme).

\section{Discussão}

Dentre as limitaçóes deste estudo, destaca-se a censura ao falar do priapismo e da disfunção sexual, que pode ter se dado pelo fato de as entrevistas terem sido realizadas no próprio centro de saúde. Houve também o fato de os participantes serem dependentes exclusivos do Sistema Único de Saúde e pertencerem ao mesmo extrato social, o que pode ter restringido as experiências comuns à mesma classe social. Para superar tais limitaçóes, recomendamos a ampliação de estudos para outros cenários de cuidado, para buscar alcançar homens de classe sociais diversas.

Embora seja uma doença hereditária, situação que resultaria num aprendizado sobre a doença e os cuidados necessários para preservação da saúde desde a infância, os participantes deste estudo tiveram o diagnóstico tardio, implicando em adotar mudanças no padrão de cuidados anterior. Também vale destacar que essa experiência é marcada pela dor que progressivamente incapacita os homens para conduzirem suas vidas conforme a sociedade espera deles, enquanto seres sexuados, trabalhadores, ativos, independentes e capazes de produzir recursos para seu próprio sustento e a manutenção de seu grupo familiar.

Desse modo, ao perceberem que seus planos são frustrados pela doença, os homens concebem a doença como destruidora, porém a ressignificam e a compreendem como uma lição sobre o cuidar de si mesmo. Esse novo significado implica na mudança de comportamento e no desenvolvimento de práticas cuidativas, que são mediadas pela presença de profissionais de saúde e pelo suporte do recurso digital, possibilitado pela internet. 
Ao terem emergido as mudanças decorrentes da doença falciforme, as práticas adotadas pelos homens encontram-se direcionadas à minimização da ocorrência de novos eventos e complicaçôes - e, consequentemente, dos fatores limitadores gerados pela doença. Tais mudanças estão permeadas pelo imaginário do alcance de um status satisfatório de qualidade de vida.

Entrelaçados a essas transformaçóes, atributos de masculinidade hegemônica, como força, virilidade e invulnerabilidade, incitam nos homens a exposição a riscos, a pratica de hábitos não saudáveis, como alcoolismo e tabagismo, o desprezo e a desvalorização do autocuidado, causando resistência à procura pelos serviços de saúde. ${ }^{(9-11)}$

Envolvidos em um ideário de masculinidade hegemônica, que representa um modelo de construção social do masculino centralizador, dominante, ainda vigente, e que imprime nos homens expectativas normativas relacionadas à masculinidade exigem que eles sejam fisicamente duros e destemidos diante de riscos ou perigos. ${ }^{(9)}$ Homens formados para corresponder a esses referenciais apresentam descontrole das doenças, aderem com dificuldade às novas mudanças alimentares e ao uso contínuo de medicamentos e relutam em buscar ajuda e a discutir sobre sua saúde. ${ }^{(12)}$ Todavia, a dor e o adoecer crônico reconfiguram os lugares do masculino no universo do cuidado, alterando posiçôes sociais, afetivas/relacionais e físicas, e fazem emergir a sensibilidade, a motivação e a aceitação da doença e do tratamento. ${ }^{(10,11)}$

Neste estudo, os homens destacaram tudo o que a doença os impede de realizar e como esses obstáculos afetam os modelos de masculinidades que os influenciam desde a apresentação de seus corpos até a maneira como ele se comporta na intimidade. Há um destaque para as experiências dolorosas e a do priapismo, que afetam as dimensóes da vida dos adoecidos, tanto os surpreendendo de forma inesperada e interrompendo suas atividades cotidianas, quanto persistindo de maneira crônica e fatigante, esgotando suas energias para engajar-se nas interaçôes. ${ }^{(13)}$

Ao se depararem com a ameaça expressiva de comprometimento do ideal de masculinidade pelas complicações, seja a capacidade para o trabalho, a provisão do lar e a tolerância à dor, os homens expressam preocupação com o cuidado à saúde e referem a dificuldade para exercer livremente o autocuidado, considerando a não legitimidade de seus pares e da sociedade, que ainda não reconhece o homem como sujeito que necessita de cuidados. ${ }^{(9)}$

As alteraçôes hormonais advindas da doença ou do tratamento com a hidroxiureia implicam na redução do desempenho sexual, frustrando as expectativas sexuais e reprodutivas, podendo comprometer $\mathrm{o}$ atributo de virilidade masculina. ${ }^{(14,15)}$ Estudo revelou que as preocupaçóes com a possibilidade de falhar no encontro sexual, o medo de ter um filho com a doença e a dificuldade de se manter num emprego repercutem no exercício da sexualidade e impedem realização de projetos de paternidade. ${ }^{(16)}$ Além disso, o priapismo é percebido como défice de saúde genital, declínio da função sexual e causa de constrangimentos nas unidades de emergência e nas interações íntimas. ${ }^{(17)}$

Em face dessas vivências intimamente ligadas ao ideário de masculinização, as incertezas quanto ao futuro, ante o adoecimento crônico, são intensificadas, na medida em que os participantes se sentem afastados ou excluídos do mundo do trabalho, dificultando sua permanência e ascensão social e resultando em sentimentos de menor valia por si mesmos. Isso porque os valores moral e social do trabalho lhes assegurariam tanto a autonomia, a independência e a realização pessoal como a conquista da identidade e o status social de trabalhador. ${ }^{(18,19)}$

Em razão de sofrerem com os impactos sociais, por não alcançarem uma educação formal, pessoas com doença falciforme necessitam se dedicar a trabalhos fisicamente mais exigentes. Porém, elas podem ser incapazes de trabalhar ou manter um emprego estável, apresentando problemas de saúde e crises álgicas frequentes. Esses fatores afetam a capacidade de obter cuidados preventivos consistentes, tornando o autocuidado ainda mais importante. ${ }^{(20)}$

Somada a esses impactos e em consequência das dores constantes, a depressão nas pessoas com doença falciforme é mais elevada do que na população geral. No entanto, a depressão na doença falciforme também resulta do sofrimento causado por atitudes 
discriminatórias de pessoas que reduzem os adoecidos a estereótipos, destinando-lhes tratamentos descorteses e desiguais, principalmente nas unidades de emergência, imputando-lhes mais padecimento do que a própria doença e os desanimando a buscar ajuda, quando necessária, devido à antecipação do estigma. ${ }^{(21,22)}$

Tendo sua situação de saúde mental comprometida e intensificada pelo processo de estigmatização, o padecimento gerado pela doença crônica conduz os homens a uma rotina rígida de cuidados, que os recorda da necessidade de estar vigilante para com seu corpo e sua saúde. Nesse sentido, os homens percebem que contrariam os modelos de masculinidade hegemônicos ainda vigentes no contexto atual brasileiro, na medida em que atitudes de cuidado se opóe à idealizada imagem do homem "invulnerável".

As dores excruciantes da doença falciforme situam a pessoa sobre a própria fragilidade e anunciam complicaçóes que podem conduzi-la à morte. A percepção da vulnerabilidade é positiva, pois reforça, no indivíduo, a necessidade de aderir às medidas de autocuidado; por outro lado, pode ampliar o sofrimento psíquico quando este se depara sem recursos materiais e rede de apoio para cuidar de si. Estreitar-se às redes de apoio possibilita que as pessoas que convivem com a doença falciforme ampliem o planejamento de intervençóes de caráter psicossocial, de modo eficaz e capaz de promover a qualidade vida. ${ }^{(23)}$

Como suporte para o enfrentamento dos múltiplos impactos, as redes de apoio podem se encontrar fragilizadas, devido ao processo de autoisolamento e isolamento social causados pelo adoecimento. Os homens com doença falciforme necessitam ser estimulados a participar de associaçóes e grupos de ajuda que favoreçam interaçóes positivas, aprendizados e construção de vínculos. ${ }^{(24)}$

\section{Conclusão}

Este estudo permitiu compreender que homens com doença falciforme se reconhecem enquanto seres forjados pelas expectativas sociais de sexo, com limitaçóes impostas por uma doença que coloca em cheque os valores das masculinidades hegemônicas, fazendo com que reflitam sobre as pressóes do machismo e seu lugar de sujeito do cuidado, com valorização do cuidar de si. Os achados fornecem implicaçôes substanciais para a prática assistencial em enfermagem e na saúde, tornando mais evidente a análise sob o cotidiano, os impactos gerados pela doença e o marcador social das masculinidades como componentes essenciais para a clínica. O estudo indica ainda um aprofundamento sobre as estratégias de enfrentamento adotadas pelos homens diante dos impactos da doença falciforme e suscita o desenvolvimento de açóes direcionadas para amenizá-los.

\section{Colaborações}

Sousa AR, Jesus AC, Andrade RCS, Lopes TFA, Jenerette CM, Carvalho ESS e Pereira A declaram que contribuíram com a concepção do estudo, análise e interpretação dos dados, redação do artigo, revisão crítica relevante do conteúdo intelectual e aprovação da versão final a ser publicada.

\section{Referências}

1. Soares LF, Lima EM, Silva JA, Fernandes SS, Silva KM, Lins SP, et al. [Prevalence of hemoglobin variants in quilombola communities in the state of Piauí, Brazil]. Cien Saude Colet. 2017;22(11):3773-80. Portuguese.

2. Arduini GA, Rodrigues LP, Trovó de Marqui AB. Mortality by sickle cell disease in Brazil. Rev Bras Hematol Hemoter. 2017;39(1):52-6.

3. Lobo CL, Nascimento EM, Jesus LJ, Freitas TG, Lugon JR, Ballas SK. Mortality in children, adolescents and adults with sickle cell anemia in Rio de Janeiro, Brazil. Rev Bras Hematol Hemoter. 2018;40(1):3742.

4. Neumayr LD, Hoppe CC, Brown C. Sickle cell disease: current treatment and emerging therapies. Am J Manag Care. 2019;25(18 Suppl):S335-43.

5. Pereira J, Klein C, Meyer DE. PNAISH: uma análise de sua dimensão educativa na perspectiva de gênero. Saude Soc. 2019;28(2):132-46.

6. Barsaglini RA, Paz KM, Lemos PL. Qualidade de vida e cuidado às pessoas com doença falciforme. Interface (Botucatu). 2015;19(52):195-200.

7. Tong A, Sainsbury P, Craig J. Consolidated criteria for reporting qualitative research (COREQ): a 32-item checklist for interviews and focus groups. Int J Qual Health Care. 2007;19(6):349-57. 
8. Lefevre F, Lefevre AM. Discourse of the collective subject: social representations and communication interventions. Texto Contexto Enferm. 2014;23(2):502-7.

9. Connell RW, Messerschmidt JW. Masculinidade hegemônica: repensando o conceito. Rev Estud Fem. 2013;21(1):241-82.

10. Yoshida VC, Andrade MG. Health care from the view of male workers with chronic diseases. Interface (Botucatu). 2016;20(58):597-610.

11. Santos RN, Bellato R, Araújo LF, Almeida KB, Souza IP. Men's position in family care on situations of chronic illness. Rev Esc Enferm USP. 2018;52:e03398.

12. Stergiou-Kita M, Mansfield E, Bezo R, Colantonio A, Garritano E, Lafrance $M$, et al. Danger zone: Men, masculinity and occupational health and safety in high risk occupations. Saf Sci. 2015;80:213-20.

13. Huang AW, Muneyyirci-Delale 0 . Reproductive endocrine issues in men with sickle cell anemia. Andrology. 2017;5(4):679-90.

14. DeBaun MR. Hydroxyurea therapy contributes to infertility in adult men with sickle cell disease: a review. Expert Rev Hematol. 2014;7(6):76773.

15. Luchtman-Jones L, Pressel S, Hilliard L, Brown RC, Smith MG, Thompson AA, et al. Effects of hydroxyurea treatment for patients with hemoglobin SC disease. Am J Hematol. 2016;91(2):238-42.

16. Cordeiro RC, Ferreira SL, Santos AC. The illness of women and men with sickle cell disease: a Grounded Theory study. Rev Lat Am Enfermagem. 2015;23(6):1113-20.
17. Maia HA, Alvaia MA, Carneiro JM, Xavier AS, Bessa Júnior J, Carvalho ES. Access of men with sickle cell disease and priapism in emergency services. Braz J Pain. 2019;2(1):20-6.

18. Barros CT, Gontijo DT, Lyra J, Lima LS, Monteiro EM. "Mas se o homem cuidar da saúde fica meio que paradoxal ao trabalho": relação entre masculinidades e cuidado à saúde para homens jovens em formação profissional. Saude Soc. 2018;27(2):423-34.

19. Sousa AR, Queiroz AM, Florencio RM, Portela PP, Fernandes JD, Pereira A. Homens nos serviços de atenção básica à saúde: repercussões da construção social das masculinidades. Rev Baiana Enferm. 2016;30(3):1-10.

20. Matthie N, Jenerette C, McMillan S. Role of self-care in sickle cell disease. Pain Manag Nurs. 2015 Jun;16(3):257-66.

21. Raji SO, Lawani A0, James BO. Prevalence and correlates of major depression among Nigerian adults with sickle cell disease. Int J Psychiatry Med. 2016 Jul;51(5):456-66.

22. Holloway BM, McGill LS, Bediako SM. Depressive symptoms and sickle cell pain: the moderating role of internalized stigma. Stigma Health. 2017;2(4):271-80.

23. Dias TL, Leite LL. Rede de apoio social e afetivo e estratégias de enfrentamento na doença falciforme: um olhar sobre a pessoa e a família. Psicol Rev. 2014;20(2):353-73.

24. Gomes MV, Xavier AD, Carvalho ES, Cordeiro RC, Ferreira SL, Morbeck AD. "Waiting for a miracle": Spirituality/Religiosity in coping with sickle cell disease. Rev Bras Enferm. 2019;72(6):1554-61. 